\title{
Effect of Different Concentrations of Detergent on Dissolved Oxygen Consumption in Anabas testudineus
}

\author{
Emi Mathew ${ }^{1}$, Sunitha P. T. ${ }^{2}$, Philip Litto Thomas ${ }^{2}$ \\ ${ }^{I}$ School of Biosciences, Mahatma Gandhi University, India \\ ${ }^{2}$ Department of Zoology, St. Berchmans College, India
}

\begin{abstract}
Kerala, on the South Western tip of Peninsular India is blessed with the South western and South Eastern monsoon which contributes to its vast fresh water bodies. But pollution of these water bodies has created physiological stress on its aquatic fauna. Among various forms of pollution in water bodies, detergent pollution has an immediate and detrimental effect on the aquatic fauna. Anabas testudineus, a common fresh water fish in Kerala was used in our study to determine the effect of detergent pollution on the fish's breathing. Three different concentrations of a popular brand of detergent were prepared and the amounts of Dissolved Oxygen consumed by fishes exposed to the detergent were determined using Winkler's method. Our study demonstrated that Dissolved Oxygen consumption in Anabas testudineus increases in the presence of detergent. This is due to the stress caused by the detergent on the normal physiological activities of the fish. Draining of domestic sewage containing detergents into water bodies adversely affect its aquatic fauna.

Keywords: Anabas testudineus, Detergent, Dissolved Oxygen, Fresh water, Stress
\end{abstract}

\section{INTRODUCTION}

Water, like air, is one of the most important and precious natural resource and a regular and plentiful supply of clean water is essential for the survival and health of most living organisms. The state of Kerala in Indian Union is one among the rainiest areas in the world. [1] Unfortunately, many of its water bodies are becoming increasingly murky, smelly and chocked with growth of algae. Most of the rivers have become darkened with chemicals, oils, sewage etc.[2] Indiscriminate use and dumping of domestic sewage into fresh water resources has taken its toll on the various life forms of the aquatic habitat. A number of fish species that were abundant years ago have failed to cope up with the stress caused by increased concentrations of various chemicals that are poured into the water bodies. [3] An indicator of pollution in water is its amount of Dissolved Oxygen (DO). Dissolved Oxygen's presence in water is a positive sign, but low levels are a sign of severe pollution. Water with consistently high levels of DO is considered healthy and capable of supporting many different kinds of aquatic organisms. [4] DO in water generally come from one of two sources. Most DO comes from the atmosphere and tumbling water mixes atmospheric oxygen. Another source of DO is photosynthesis by plants.

Kuttanad, often referred to as the' rice bowl of Kerala' is an area covering $265.93 \mathrm{Sq}$. km reclaimed from the backwaters of Lake Vembanad. At -2.2 MSL, it is one of the few places in the world where farming is carried out below sea level. People of Kuttanad depended on the water from rivers and other water bodies for their daily requirements. These waters were havens for wide variety of aquatic fauna. But promiscuous use of pesticides and fertilizers has made these water bodies unsuitable for human use. Besides, many studies have reported the ill effects of fertilizers and pesticides on the fauna and flora of aquatic systems. [5] However, apart from fertilizers and pesticides, another harmful chemical agent that often goes unnoticed is detergents.

Detergents are used in all households for washing purposes and in almost all households of Kuttanad, domestic sewage is dumped into nearby water bodies. Detergents are not fully degraded even after sewage treatment and their discharge in to the river cause serious pollutions problems. Detergents can also be wetting agents which lower the surface tension of water and act as clearing agents. Enzymes present in detergent cause several types of allergies. Phosphate in detergents favors the growth of algae which uses up most of the available oxygen in the water causing the death of aquatic organisms. [6]

Vast majority of fishes cannot live out of water for any length of time. As a general rule, fishes with wide external gill openings die more rapidly than those in which the apertures are reduced. Those fishes which also survive out of water have a gill structure which enables then to keep sufficient moisture trapped between the filaments to prevent both collapse of the folds and the drying-out of the gill surface.[7] Anabas testudineus is a common food fish abundant in tanks, ponds, streams and lakes of India. They are perch- like fishes (Order: Perciforms) placed under the Sub order-Anabantidae, possessing a labyrinth like accessory breathing organ on either side of the head [8]. Anabas has the habit of migrating from pond to pond. When in water, the fish frequently comes to the surface to breath air. The air swallowed by Anabas is taken into two chamber situated one on each side above the gills, forming outgrowths from the ordinary brachial chambers, richly supplied with 
fine blood vessels and covered with thin epithelium.[9]. Presence of accessory respiratory organs help Anabas survive in waters low in Oxygen levels.

It is in this juncture that we proposed to study the effect of detergents on breathing rates of fishes. Our study aims to understand the effect of various concentrations of detergents on Oxygen consumption of Anabas testudineus. Anabas was selected for this study due to its sturdy nature with which it can withstand the stress much better than other fishes.

\section{MATERIALS \& METHODS}

\subsection{Experimental setup}

Study fishes were collected from a fish hatchery. Young fishes averaging $10 \mathrm{~g}$ were selected. Water samples for the experiment were collected from a relatively unpolluted pond. Three different concentrations (100ppm, 500ppm and 1000ppm) of the popular detergent, 'Surf' was prepared in the sample water. Dissolved Oxygen (DO) content of the sample water was estimated using Winkler's method. Transferred a fish each into three jars with the said concentrations of the detergent and kept for one hour. Similarly three control jars with 100ppm, 500ppm and 1000ppm detergent were kept as controls. After one hour, water samples were collected from the six jars using siphon and estimated their DO content employing Winkler's method. Difference between the amounts of DO in the sample with only detergent and that with both detergent and fish gave the amount of DO consumed by the fish for that particular concentration of detergent. Similarly, DO consumed by fishes in other water samples was calculated. All experiments were repeated 5 times.

\subsection{Estimation of Dissolved Oxygen (DO)}

Water sample for estimation after the experiment was taken in $250 \mathrm{~mL}$ bottles taking care to reduce the contact of this water to air and not to induce any air bubble in the sample bottle. The bottle was closed with a stopper. $1 \mathrm{~mL}$ of Manganous sulphate and $1 \mathrm{~mL}$ of alkaline iodide were poured into the bottle using separate pipettes. Shook well and allowed to settle down. Shook the bottle again and $2 \mathrm{~mL}$ of concentrated Sulphuric acid was added to this mixture and shook vigorously to digest the precipitate. $50 \mathrm{~mL}$ of this solution was pipetted out into a conical flask. It was then titrated against Sodium Thiosulphate solution taken in the burette until the brown colour of iodine almost disappeared. To this, added 5 drops of starch solution. The end point was marked by the first complete disappearance of blue colour.

\section{RESULTS}

Dissolved Oxygen in the water sample was estimated before adding the detergent or introducing the fishes and the values averaged at $9.71 \mathrm{mg} / \mathrm{L}$. This reading was taken as the control. DO concentration near to 10 $\mathrm{mg} / \mathrm{L}$ indicated that the water sample collected for the experiment contained sufficient amount of dissolved Oxygen for the survival of fishes. Sample water treated with $100 \mathrm{ppm}$ of detergent for 1 hour showed a mean decrease in DO of $0.19 \mathrm{mg} / \mathrm{L}$ from the control. With increased concentration of detergent at $500 \mathrm{ppm}$ for 1 hour, DO further decreased by $0.51 \mathrm{mg} / \mathrm{L}$ from the control. This trend continued also with the sample water treated with a detergent concentration of $1000 \mathrm{ppm}$ for $1 \mathrm{hr}$. where a mean decrease in DO of $0.83 \mathrm{mg} / \mathrm{L}$ from the control was noted. This decrease in DO content of sample water treated with detergents was due to the presence of Phosphates in detergents which readily react with dissolved Oxygen.

Table: 1- Dissolved Oxygen Levels under Different Treatments

\begin{tabular}{|c|c|c|c|c|}
\hline $\begin{array}{c}\text { Concentration of } \\
\text { Detergent }\end{array}$ & $\begin{array}{c}\text { DO (mg/L) } \\
\text { Detergent alone }\end{array}$ & $\begin{array}{c}\text { DO(mg/L) } \\
\text { Detergent \& Fish }\end{array}$ & $\begin{array}{c}\text { DO(mg/L) consumed } \\
\text { by Fish }\end{array}$ & $\begin{array}{c}\text { DO consumption } \\
\text { (mg/L/hr/g body wt.) }\end{array}$ \\
\hline $0 \mathrm{ppm}$ & 9.71 & 7.01 & 2.7 & 0.26 \\
\hline $100 \mathrm{ppm}$ & 9.52 & 6.32 & 3.2 & 0.31 \\
\hline $500 \mathrm{ppm}$ & 9.2 & 5.36 & 3.84 & 0.39 \\
\hline $1000 \mathrm{ppm}$ & 8.88 & 3.5 & 5.38 & 0.53 \\
\hline
\end{tabular}

DO- Dissolved Oxygen (All treatments were of 1 hour duration and the values are Arithmetic Mean of 5 independent experiments)

When experimental fishes were introduced into water containing $100 \mathrm{ppm}$ of detergent, they started showing discomfort within 10 minutes and began to move around rapidly. With increased concentrations of the detergent at $500 \mathrm{ppm}$ and $1000 \mathrm{ppm}$, the time lag for rapid movements reduced to around 5 minutes and 2 minutes respectively. However, in all the experiments, the fishes appeared inactive later and rested at the bottom of the vessel. But, they continued to breathe rapidly and the mucous on the body surface started to come off. This phenomenon was more manifest in the water with $1000 \mathrm{ppm}$ detergent. Estimation of DO consumed by the fishes showed an increasing trend with the increase in concentration of the detergent. Fishes used in control experiment (with no detergent added) showed a DO consumption of $2.7 \mathrm{mg} / \mathrm{L} / \mathrm{hr}$. Fishes kept at $100 \mathrm{ppm}$ of 
detergent concentration showed a mean DO consumption of $3.2 \mathrm{mg} / \mathrm{L} / \mathrm{hr}$. With the detergent concentrations at $500 \mathrm{ppm}$ and $1000 \mathrm{ppm}$, the mean DO consumption reached $3.84 \mathrm{mg} / \mathrm{L} / \mathrm{hr}$ and $5.38 \mathrm{mg} / \mathrm{L} / \mathrm{hr}$ respectively. All the experimental fishes weighed between $9.8 \mathrm{~g}$ and $10.3 \mathrm{~g}$. Mean DO consumption per gram body weight of the fishes used in the experiments were calculated and is shown in the last column of Table 1. This data also indicates an increased consumption of DO by the fishes under increased concentrations of the detergent.

Figure: 1- Dissolved Oxygen Consumed by Fishes at Different Concentrations of the Detergent

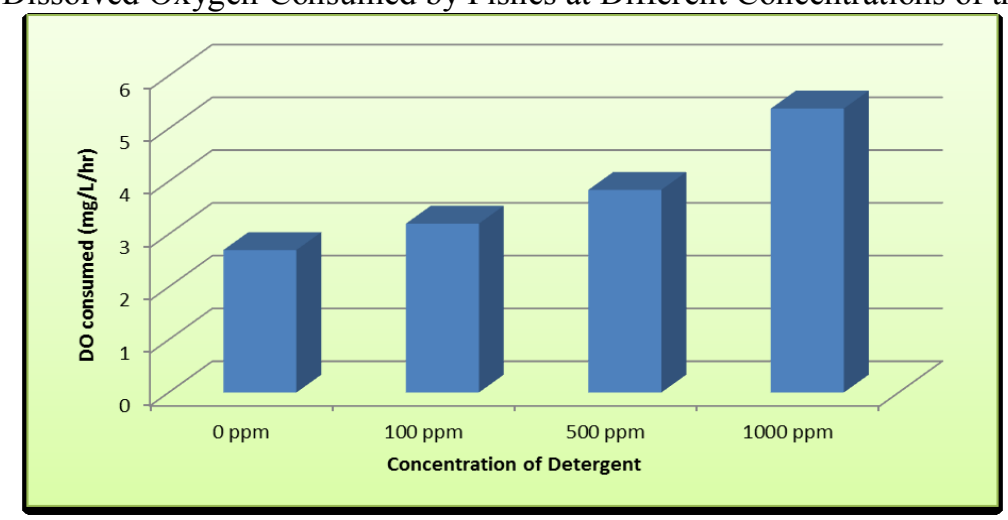

IV. DISCUSSION \& CONCLUSION

From this experiment it is observed that the detergent had a severe impact on the experimental fish.

Anabas has large respiratory capacity than other fresh water fishes due to the presence of accessory respiratory organs. Even with this capacity, the fish's DO consumption increased when it was exposed to the water containing detergent. With increase in concentration of the detergent, increased breathing and signs of distress were exhibited by the fish. Even though Anabas testudineus is very sturdy in tiding over stressful environment, presence of detergents proved detrimental. Other less sturdy aquatic fauna would easily succumb to increased concentrations of detergents in their environment.

Soaps and detergents are the main cleansing agents used in households. Most of the ingredients of soap are biodegradable, but that of detergents are not biodegradable. Hence detergents cause more water pollution than soap. In areas like Kuttanad, where most households are by the banks of rivers and canals, waste water is often expelled into the water bodies. During earlier times when the use of detergents was not so prevalent, people relied on soaps for washing purposes. This might not have created much distress to the aquatic fauna.

But nowadays almost all households use detergents for washing purposes and in most cases, the sewage water is discharged into the water bodies. People need to be made aware of the adverse causalities of detergents on various forms of aquatic life. Sewage water generated from households should not be allowed to be discharged directly into the water bodies. Better sewage treatment facilities have to be looked into for the protection of these water bodies.

\section{Acknowledgements}

The authors wish to acknowledge the help rendered by Salini Sreekumar, Dept. of Zoology, St. Berchmans College, Changanassery, India during sample collection and experiments.

\section{REFERENCES}

[1] Ananthakrishnan, R. and Soman, M. K. The onset of the southwest monsoon over Kerala: 1901-1980. J. Climatol., 8, 1988, 283296.

[2] Jayaraman, P. R., T. Ganga Devi, and T. Vasudevan Nayar. "Water Quality Studies on Karamana River, Thiruvananthapuram District, South Kerala, India." Pollution Research 22.1 2003: 89-100.

[3] Sheela A.M., Letha J. and Joseph S. Environmental status of a tropical lake system. Environ Monit Assess,. 180, (1-4) 2011, 427-49.

[4] Sharma B.K. and Miss. H. Kaur, Water Pollution IInd edition.(New Delhi: Goel publishing house,1997-1998)

[5] Babu V, Unnikrishnan P, Anu G. and Nair SM. Distribution of organophosphorus pesticides in the bed sediments of a backwater system located in an agricultural watershed: influence of seasonal intrusion of seawater. Arch Environ Contam Toxicol., 60(4,) 2011, 597-609.

[6] Dara S.S. A Text book of Environmental Chemistry and Pollution (New Delhi: S. Chand and Co. Ltd., 1993)

[7] Fry E.E.J., The aquatic respiration of fish 1st edition (New York: Academic Press, 1957)

[8] Hughes G.M. and Morgan. M., The structure of gills in relation to their respiratory function IIIrd edition ( London: British museum, 1973)

[9] J.R. Norman, A History of Fishes IIIrd edition (DSC British museum London, 1975) 